See Article page e161.

\section{Commentary: Designing better broken hearts: Modeling regurgitant bicuspid aortic valve disease}

\author{
Madeline L. Fryer, MMSc, ${ }^{\mathrm{a}}$ and \\ Leora B. Balsam, $\mathrm{MD}^{\mathrm{b}}$
}

Unlike mitral valve regurgitation, for which repair is the standard of care for degenerative disease, severe aortic valvular insufficiency is more commonly treated with valve replacement. Despite a number of staunch advocates, the broader use of aortic valve repair has been hampered by lack of standardization of repair techniques and scant data demonstrating reproducibility and long-term durability. ${ }^{1}$ Potential advantages of repair include freedom from complications specific to replacement, including structural valve degeneration and patient-prosthesis mismatch for bioprostheses, bleeding complications for mechanical valves, and lower risk of endocarditis. Repair is also particularly appealing for the pediatric population, who may outgrow valve prostheses. Clinical data to date, however, suggest that patients undergoing repair have greater early reintervention rates compared with those undergoing valve replacement. ${ }^{2}$

In this issue of the Journal, Zhu and colleagues ${ }^{3}$ describe an ex vivo model of regurgitant bicuspid aortic valve (BAV) that they have created for practice of repair techniques. The model consists of a bovine aortic root in which the valve is surgically modified to mimic the most common BAV morphology, fusion of the left and right cusps (Sievers type I BAV). ${ }^{4}$ To produce prolapse of the fused leaflet, the leftright commissure height is lowered $10 \mathrm{~mm}$ below the native height. The root is mounted and connected to a left heart simulator, allowing for quantitative assessment of valvular

\footnotetext{
From the ${ }^{\mathrm{a}}$ University of Massachusetts Medical School; and ${ }^{\mathrm{b}}$ Division of Cardiac Surgery, UMass Memorial Medical Center, Worcester, Mass.

Disclosures: The authors reported no conflicts of interest.

The Journal policy requires editors and reviewers to disclose conflicts of interest and to decline handling or reviewing manuscripts for which they may have a conflict of interest. The editors and reviewers of this article have no conflicts of interest.

Received for publication July 2, 2020; revisions received July 2, 2020; accepted for publication July 2, 2020; available ahead of print July 13, 2020.

Address for reprints: Leora B. Balsam, MD, Division of Cardiac Surgery, UMass Memorial Medical Center, University Campus, 55 Lake Ave North, Worcester, MA 01655 (E-mail: leora.balsam@umassmemorial.org).

J Thorac Cardiovasc Surg 2022;163:e173-4

$0022-5223 / \$ 36.00$

Copyright (c) 2020 by The American Association for Thoracic Surgery

https://doi.org/10.1016/j.jtcvs.2020.07.018
}

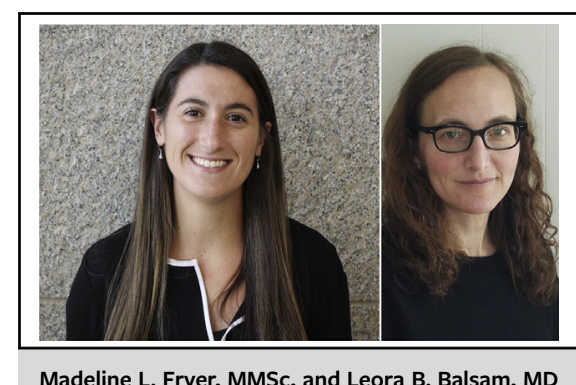

\begin{abstract}
CENTRAL MESSAGE
An ex vivo model of bicuspid aortic valve regurgitation is a useful tool for assessing repair techniques but is limited by the moderate degree of regurgitation and lack of long-term hemodynamic data.
\end{abstract}

function under prespecified hemodynamic conditions. The model is an extension of previous work by the same authors in which they evaluated a trileaflet porcine aortic valve model with cusp prolapse using the left heart simulator. ${ }^{5}$ In the present study, they not only modify the valve to create a functionally bicuspid valve, but they also examine the efficacy of specific repair techniques to limit valvular regurgitation.

Strengths of this model are its relatively low cost, reproducibility, and modifiability to recapitulate patient-specific anatomy for comparison of short-term efficacy of repair techniques. The model builds upon previous work from the University of Ottawa group using porcine aortic roots to assess the effect of aortic valve annular geometry ${ }^{6}$ and repair biomaterials $^{7}$ on the hemodynamic severity of regurgitation in an ex vivo model of tricuspid aortic valvular insufficiency.

The model has some limitations as well. Other groups have used mathematical finite element modeling to study aortic valvular insuffiency, ${ }^{8}$ which offers information regarding cusp stress; such information is not obtained from the present model. Moreover, while symptomatic manifestations cannot be inferred ex vivo, this model is also unable to recapitulate left ventricular dilation, declining left ventricular ejection fraction, and fails to meet objective criteria that would warrant surgical intervention in patients. ${ }^{9}$ An average regurgitant fraction of $28.6 \%$ was achieved, which corresponds to moderate aortic insufficiency; a more clinically relevant model would have an 
average regurgitant fraction greater than $50 \%$. One cannot extrapolate that a severely regurgitant valve can be successful repaired with the same techniques as a moderately regurgitant valve. An additional constraint of the study is the lack of long-term hemodynamic analysis; in fact, analysis was limited to 10 cycles only. This study design does little to allay concerns regarding durability of repair techniques for aortic regurgitation.

Despite these limitations, the work presented by Zhu and colleagues $^{3}$ still remains an important step forward in the development of a reproducible model of BAV-related regurgitation for future study of repair techniques.

\section{References}

1. Arnaoutakis GJ, Sultan I, Siki M, Bavaria JE. Bicuspid aortic valve repair: systematic review on long-term outcomes. Ann Cardiothorac Surg. 2019;8: 302-12.

2. Wong CHM, Chan JSK, Sanli D, Rahimli R, Harky A. Aortic valve repair or replacement in patients with aortic regurgitation: a systematic review and metaanalysis. J Card Surg. 2019;34:377-84.
3. Zhu Y, Imbrie-Moore AM, Paulsen MJ, Priromprintr B, Wang H, Lucian HJ, et al. Novel bicuspid aortic valve model with aortic regurgitation for hemodynamics status analysis using an ex vivo simulator. J Thorac Cardiovasc Surg. 2022;163: e161-71.

4. Sievers HH, Schmidtke C. A classification system for the bicuspid aortic valve from 304 surgical specimens. J Thorac Cardiovasc Surg. 2007;133:1226-33.

5. Zhu Y, Imbrie-Moore AM, Paulsen MJ, Priromprintr B, Park MH, Wang H, et al. A novel aortic regurgitation model from cusp prolapse with hemodynamic validation using an ex vivo left heart simulator. J Cardiovasc Transl Res. 2021;14:283-9.

6. Al-Atassi T, Toeg HD, Jafar R, Sohmer B, Labrosse M, Boodhwani M. Impact of aortic annular geometry on aortic valve insufficiency: insights from a preclinical, ex vivo, porcine model. J Thorac Cardiovasc Surg. 2015;150:656-64.e1.

7. Toeg HD, Abessi O, Al-Atassi T, de Kerchove L, El-Khoury G, Labrosse M, et al. Finding the ideal biomaterial for aortic valve repair with ex vivo porcine left heart simulator and finite element modeling. J Thorac Cardiovasc Surg. 2014;148: 1739-45.e1.

8. Labrosse MR, Boodhwani M, Sohmer B, Beller CJ. Modeling leaflet correction techniques in aortic valve repair: a finite element study. J Biomech. 2011;44: 2292-8.

9. Nishimura RA, Otto CM, Bonow RO, Carabello BA, Erwin JP, Guyton RA, et al. 2014 AHA/ACC guideline for the management of patients with valvular heart disease: executive summary: a report of the American College of Cardiology/American Heart Association task force on practice guidelines. J Am Coll Cardiol. 2014;63: 2438-88.
See Article page e161.

\section{Commentary: Valvular mimicry in simulation - espice, adspice, prospice}

\section{Thomas G. Gleason, MD, and Sari Aranki, MD}

In their article in this issue of the Journal, Zhu and colleagues $^{1}$ have identified another role for their ex vivo cardiac simulator, previously developed and reported on by Dr Woo's research team. ${ }^{1-8}$ Their simulator includes a pulsatile piston pump with an impedance adapter, compliance chambers ("ventricular" and "aortic" chambers), and an adjustable peripheral resistance. It is

From the Division of Cardiac Surgery, Brigham \& Women's Hospital and Harvard Medical School, Boston, Mass.

Disclosures: Dr Gleason serves on a Medical Advisory Board for Abbott. Aranki has reported no conflicts of interest.

The Journal policy requires editors and reviewers to disclose conflicts of interest and to decline handling or reviewing manuscripts for which they may have a conflict of interest. The editors and reviewers of this article have no conflicts of interest.

Received for publication July 19, 2020; revisions received July 19, 2020; accepted for publication July 21, 2020; available ahead of print July 24, 2020.

Address for reprints: Thomas G. Gleason, MD, Division of Cardiac Surgery, Brigham \& Women's Hospital, 75 Francis St, Boston, MA 02481 (E-mail: tgleason@bwh. harvard.edu).

J Thorac Cardiovasc Surg 2022;163:e174-6

$0022-5223 / \$ 36.00$

Copyright (c) 2020 by The American Association for Thoracic Surgery

https://doi.org/10.1016/j.jtcvs.2020.07.063
Check for updates

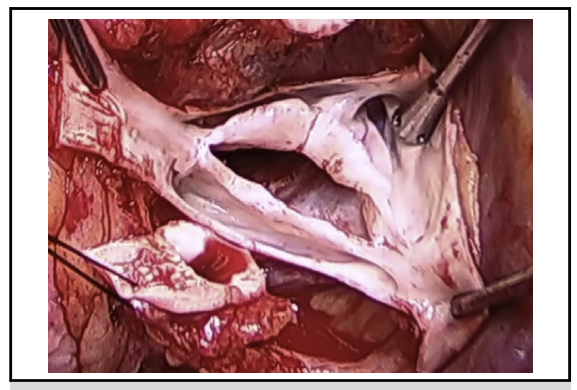

Note degree of sclerosis and fibrosis of this type 1 $\mathrm{R} / \mathrm{N}$ bicuspid aortic valve.

CENTRAL MESSAGE

Cardiac simulators with tunable morphologic valve phenotype and pathophysiologic lesion capability may be a platform for testing valve repair strategies. Validation for clinical relevance remains

equipped with high-speed videographic and echocardiographic capability, thus allowing for both visual and hemodynamic "aortic" or "mitral" valvular assessments within the similator. ${ }^{2-8}$ In this latest article from Zhu and 